\title{
Refurbishment and end of life roof membrane structure of the Teatro Verdi in Montecatini Lucca
}

\author{
C. Vannelli \\ * Canobbio Textile Engineering Srl \\ Strada Sgarbazzolo, 15053 Castelnuovo Scrivia (AL) - Italy \\ e-mail: carlo.vannelli@canobbiotextile.com,web page: https://www.canobbiotextile.com
}

\begin{abstract}
The paper focuses on a case stady of replacement of a membrane roof after 34 years of life span and on the design processes of the demounting phase, re-design and new installation, aiming to explain the potentials and the gaps of the dry assembling system in the demounting and replacement phase. The refurbishment, carried out in 2015, was aimed at substituting the PVC textile cover installed by our company in 1981.The structure (1300 sqm.) originally was born as a temporary within a protected park in the city centre of Montecatini Terme, designed and build by our company.The main constraints of the refurbishment intervention have been:

$\checkmark$ volumes to be respected following the philosophy of the original construction

$\checkmark$ less impacting color than the original white one

$\checkmark$ reuse of existing carpentry

$\checkmark$ geometry constraints.
\end{abstract}

The customer after a private competition between some companies decided to re-trust our company to work trusting in the copy of the coverage. Since at the time the model was built manually creating a shape with real fabrics as a sartorial realization, it was necessary to reconstruct the geometry with the help of laser scanner systems. In fact, the request to reuse the bearing structure built of galvanized metal tubulars, forced compliance with the original shape with a minimum tolerance approximation. The repositioning of points in space, required particular attention to recreate an efficient form respecting the starting criteria.

In addition to the Polyester/PVC cover with the same mechanical characteristics as the original one, a color that blended with the surrounding nature was chosen by the competent authorities. The fabric was produced with the black inner surface suitable for the type of programming inside the theater. Regarding the scenarios of end of life of the components, the ropes have been replaced entirely because weathering over the decades corrodes them; the old membrane has been disposed of at a specialized waste center. The old ropes were disposed at a metal recycling center.
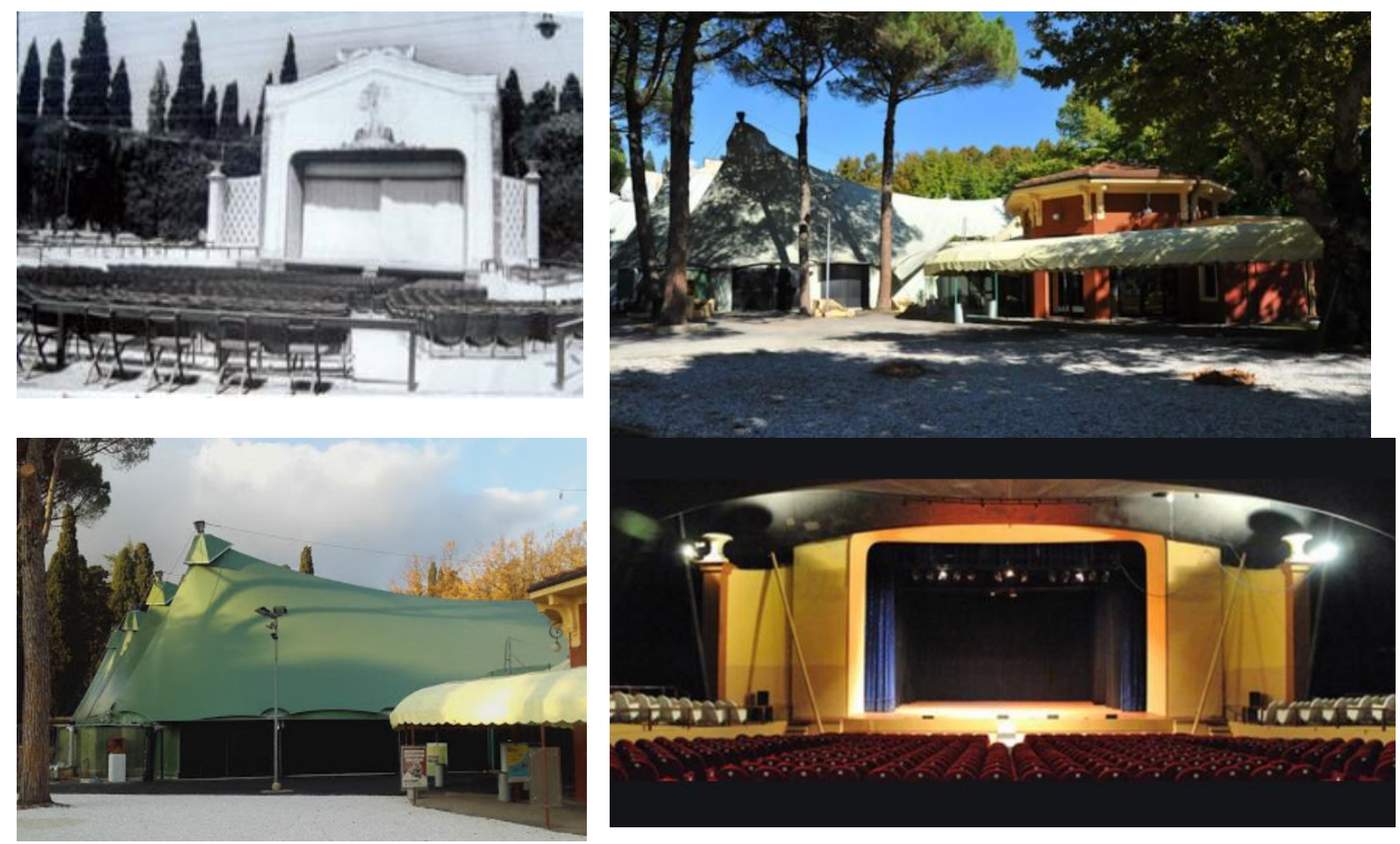

Pictures of the evolution of the structure during the years till the substitution of the roof membrane. 